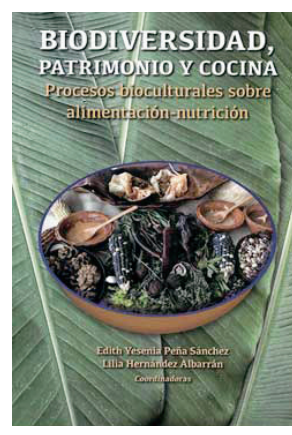

Edith Yesenia Peña Sánchez y Lilia Hernández Albarrán (Coords.). (2018). Biodiversidad, patrimonio y cocina. Procesos bioculturales sobre alimentación-nutrición. México: Secretaría de Cultura / Instituto Nacional de Antropología e Historia.

\author{
Ariadna Campos Quezada \\ ariadna.campos.quezada@gmail.com \\ Universidad Anáhuac, México Norte
}

$\mathrm{D}$ ictan los aforismos que "Se es lo que se come y se come lo que se es". Puesto que alimentarnos los unos a los otros es mucho más complejo de lo que un simple bocado puede ser. Explica Mabel García que la alimentación constituye una de las múltiples actividades de la vida cotidiana de cualquier grupo social y por su especificidad y polivalencia, adquiere un lugar central en la caracterización biológica, psicológica y cultural de la especie humana. Siendo por un lado imprescindible para la supervivencia física y el bienestar psíquico de las personas y, a su vez, crucial para la reproducción social de las sociedades humanas (2008).

Cumpliendo con esta centralidad en la vida de los individuos y sus sociedades, repensar la alimentación y la posición que estos tienen como entes biológicos, nos lleva a analizar la relación indisociable que la cultura misma tiene con la naturaleza. Así, explica Machuca que la noción de patrimonio biocultural se acerca más a la episteme de la concepciones tradicionales de las numerosas culturas, expandiendo así el referente de la alimentación y la biodiversidad, no solo en un sentido práctico-ultilitario.

Biodiversidad, patrimonio y cocina. Procesos bioculturaeles sobre alimentación-nutrición. Es una revisión crítica sobre el tratamiento de las diversas culturas alimentarias desde el enfoque del estudio de lo biocultural, se analiza su construcción teórica y sus fenómenos emergentes, tales como la patrimonialización, la turistificación y la inserción de las culturas alimentarias asimiladas como tradicionales al mercado global. Mediante once trabajos interdisciplinarios, resultado del Seminario Permanente de Cocinas en México que se realiza en la Coordinación Nacional de Antropología del Instituto Nacional de Antropología e Historia. La publicación enmarca tres ejes de investigaciones: en el primero Machuca, así como Peña y Hernández, delinea teórica y conceptualmente al patrimonio, y el enfoque biocultural aplicado a la alimentación. De la misma manera, Iturriaga revisa la historia de la evolución humana para concebir a la cultura como el vínculo de la colectivi-

CÓMO CITAR: Campos, A. (2019). Reseña del libro Biodiversidad, patrimonio y cocina. Procesos bioculturales sobre alimentación-nutrición. Dimensiones Turísticas, 3(5), 110-112. https://doi.org/10.47557/ZJBI6150 
dad humana y al hecho alimentario como un vehículo para su reproducción.

El segundo eje ilustra la práctica de lo biocultural en el quehacer cotidiano en el contexto comunitario: Hernán Cornejo revisa las concepciones aymaras referentes a la vida y el tiempo, sus técnicas y procesos, además de analizar las diversas pautas que el entorno da a la alimentación y cuerpos de sus integrantes; Esther Gallardo reivindica alimentación de la región rural de la ciudad de México, pueblos originarios que persisten aun frente al embate de las inmobiliarias, la pérdida de ecosistemas y las dinámicas de exclusión y despojo que trae consigo la cercanía con la gran urbe.

Mayán Cervantes y Diana Gómez, mediante un ejercicio de reconstrucción de la alimentación prehispánica y la biodiversidad asociada en Xochicalco Morelos, analizan los cambios y transformaciones dadas al territorio y su influencia en las elecciones alimentarias de sus habitantes, observan al huetle o hueutli «realizado en días de muertos con cada uno de sus elementos como el mole, los tamales y el chocolate», como un elemento ritual de la vida de la localidad.

Verónica Ramírez, Lilia Hernández y Yessenia Peña ofrecen dos acercamientos a la cultura del pueblo Hñähñu, a su cosmovisión y a sus relaciones con el entorno y con los entes con quienes comparten morada. Relaciones que permean en su cultura alimentaria, la cual persiste, evoluciona y se integra en el mercado, o bien, se transforma con las nuevas formas de consumo, como es el caso de su puesta en valor en el festival gastronómico de Santiago de Anaya.

Ariadna Campos y Perla Hernández, al referirse a la cultura alimentaria del pueblo Purépecha, identifican aspectos fundamentales en su reproducción, tales como las relaciones que el grupo mantiene con su entorno, su historicidad y sus representaciones; así como de la reconstrucción de la identidad culinaria como mecanismo de resistencia. Con lo anterior plantean alternativas a los proyectos de desarrollo que cotidianamente llegan a los contextos de comunidades locales.

El tercer eje, desde una óptica política, observa las relaciones de poder y las integraciones de los conocimientos locales frente a las mega industrias alimentarias, en los que Maya Pérez retoma la milpa y la labor del milpero, como un complejo cultural inscrito en la cosmovisión mesoamericana, la cual enfrenta el embate de las asimetrías en la distribución de beneficios, así como de la presión constante sobre sus territorios por parte de las grandes trasnacionales cuya lógica del mercado y la acumulación comprometen a la biodiversidad local, las relaciones comunitarias y la independencia económica de los campesinos.

Finalmente, Jim Thomas y Verónica Villa brindan un panorama referente a la biología sintética y su utilización en la elaboración de saborizantes, fragancias, aceites, productos medicinales y algunos tipos de antibióticos. Advierten los considerables riesgos de su producción, a gran escala y desregulada, para los pequeños agricultores y economías vinculadas a productos como la vainilla, la artemisa, la estevia, el azafrán y el caucho.

La cuidadosa compilación de Hernández y Peña, muestra una antropología comprometida que examina desde una mirada crítica las contribuciones teóricas y empíricas que 


\section{RESEÑA B Biodiversidad, patrimonio y cocina. Procesos bioculturales sobre alimentación-nutrición}

los diversos autores ofrecen referentes a la centralidad que la alimentación toma en la relación entre la cultura, el medio ambiente y sus repercusiones éticas, ambientales y de justicia alimentaria.

La discusión de la patrimonialización, en lo que a los estudios de turismo atañe, lleva a repensar sobre la consideración del patrimonio activable, para detener la mirada a su inclusión en el mercado y las nuevas configuraciones que se despliegan a sus portadores frente la narrativa del desarrollo y la apuesta por su inclusión en los imaginarios de la cultura nacional. Elementos expuestos a ser exportables, replicables y fácilmente trivializados sin necesariamente representar la inclusión de la distribución de los beneficios a quienes los han desarrollado. Retomando la idea de Wolf, los grupos y las sociedades a las que intervenimos o estudiamos nos son ajenos a los procesos sociales, políticos, económicos e históricos de las estructuras y naciones del mundo, su realidad está inserta y se ve influida por el macrocontexto mundial; hoy en día esto es así en cierto contexto del capitalismo neoliberal global.

\section{Referencias}

Arnaiz, M. G. (2002). La alimentación en el umbral del siglo xxl: una agenda para la investigación sociocultural en España. En Somos lo que comemos: estudios de alimentación y cultura en España (pp. 15-38). España: Ariel.

Wolf, E. (2001). Figurar el poder: ideologías de dominación y crisis. México: Centro de Investigaciones y Estudios Superiores en Antropología Social. 